\title{
Development of Risedronate Sodium-loaded Nanosponges by Experimental Design: Optimization and in vitro Characterization
}

\author{
K. D. PANDYA, N. V. SHAH*, D. Y. GOHIL, A. K. SETH, C. J. AUNDHIAAND S. S. PATEL \\ Department of Pharmacy, Sumandeep Vidyapeeth, Piparia, Vadodara-391 760, India
}

Pandya et al.: Design and Characterization of Risedronate-loaded Nanosponges

\begin{abstract}
The present investigation focussed on the development of a novel strategy to enhance the bioavailability of risedronate sodium, which has poor and erratic absorption. Nanosponges were statistically developed by full $3^{2}$ factorial design using Design of Experiment software considering concentration of polymer and stabilizer as independent variables and particle size and entrapment efficiency as experimental responses by utilizing the modified quasi-emulsion solvent diffusion technique. Optimized formulation showed 67.27 \pm $1.05 \%$ entrapment efficiency, $155.8 \pm 2.17 \mathrm{~nm}$ particle size and $-35.4 \mathrm{mV}$ of zeta potential. The data from in vitro release study showed burst release for initial $2 \mathrm{~h}$ followed by slow and sustained release up to $24 \mathrm{~h}$, which followed a diffusion-controlled release mechanism by the Higuchi model. Scanning electron microscopy study showed uniformly discrete spherical particles with porous surface without any agglomeration. Stability study demonstrated no significant changes in particle size, entrapment efficiency and in vitro release, which indicated that the nanosponge formulation was stable. In conclusion, it appeared that the nanosponges were a suitable nanocarrier system that could play a significant role in improving osteoporotic condition.
\end{abstract}

Key words: Risedronate sodium nanosponges, quasi-emulsion solvent diffusion, $3^{2}$ full factorial design, in vitro buoyancy, in vitro drug release

Osteoporosis, derived from the Greek words osteon (bone) and poros (pore), is a progressive bone disease sometime called as "silent disease" because it leads without any sign until a bone fracture occurs due to decrease in bone mass density, bone micro architecture deteriorates and alteration in varieties of bone proteins. Various treatments are available for the management of osteoporosis such as antiresorptive agents such as bisphosphonates, selective oestrogen receptor modulators, hormone replacement therapy, bone forming agents, vitamin D and analogs ${ }^{[1-7]}$.

Bisphosphonates,

characterized

under Biopharmaceutics Classification System class III category (freely soluble and poor permeability) ${ }^{[8]}$, have been used for the treatment of osteoporosis due to powerful binding affinity to bones. Nano scale formulation has significant low particle size that may lead to dramatic changes in the pharmacokinetics of drugs with poor solubility or permeability issues. As a consequence, nano formulation allows more passive diffusion and penetration of drug about 15-250 times greater than that of micro particles through the biological membranes ${ }^{[9]}$. Clinically, it was reported that primary amino-bisphosphonates have adverse effects such as esophagitis or reflux of partially dissolved formulations. The presence of nitrogen in the pyridinyl ring makes risedronate chemically distinct from other amino-bisphosphonates as it contains the nitrogen in primary amine. Risedronate is rapidly absorbed from upper gastro intestinal tract ${ }^{[10]}$ with a short biological half-life of $1.5 \mathrm{~h}$. Therefore, floating delivery system has been developed to sustain the release of drug for a longer period of time ${ }^{[11]}$.

Nanosponges (NSs) are minute particles with a size range of about a virus (100-300 nm), which have cavities that can be filled with a hydrophilic or a

This is an open access article distributed under the terms of the Creative Commons Attribution-NonCommercial-ShareAlike 3.0 License, which allows others to remix, tweak, and build upon the work non-commercially, as long as the author is credited and the new creations are licensed under the identical terms

Accepted 13 February 2019

Revised 19 September 2018

Received 07 May 2018

Indian J Pharm Sci 2019;81(2):309-316 
lipophilic drug. The sponges behave as a 3D network or scaffold that permits better entrapment of drug. As compared to other nanoparticles, NSs are porous, nontoxic and stable at high temperature up to $300^{\circ[12-17]}$. The aim of the present research work was to develop risedronate sodium (RS)-loaded NSs, using design of the experiment, for the better management of osteoporosis.

\section{MATERIALS AND METHODS}

RS was procured from Manus Aktteva Biopharma LLP, Ahmedabad, India. Eudragit RS 100, Eudragit E 12.5 , ethyl cellulose (18-22 cps), potassium hydroxide $(\mathrm{KOH})$, methanol, dichloromethane (DCM), polyvinyl alcohol (PVA) were purchased from Loba Chemie, Mumbai, India. All other chemicals used in research work were of analytical grade.

\section{Selection of solvent:}

Solvent was selected based on the maximum solubility of RS. An accurate quantity $(5 \mathrm{ml})$ of different solvents was taken in stoppered vials and excess amount of RS was added in to each solvent followed by vortexing for $10 \mathrm{~min}$. Vials were kept at $25 \pm 2^{\circ}$ under isothermal orbital shaker (MSW-132, Macro Scientific Work Pvt. Ltd., Delhi, India) for $24 \mathrm{~h}$ to attain an equilibrium concentration. The samples were centrifuged at $5000 \mathrm{rpm}$ for $15 \mathrm{~min}$ using a cooling centrifuge (C-24 BL, Remi Instrument Pvt Ltd, Mumbai, India). Supernatant was separated, diluted and analysed at $262 \mathrm{~nm}$ using UV/Vis spectrophotometer (UV-1800, Shimadzu, Kyoto, Japan).

\section{Formulation of drug-loaded NSs:}

NSs of RS were prepared by modified quasi emulsion solvent diffusion method. Accurately weighed quantity (20 mg) of RS was dissolved in methanolic $\mathrm{KOH}$ with the aid of sonication using bath sonicator (SW-4, Toshniwal Instruments Pvt., Ltd., Ajmer, India). Ethyl cellulose was dissolved in $10 \mathrm{ml}$ of methanol:DCM (1:1) solvent system. The drug solution was added to the polymer solution under sonication to make an internal organic phase. The organic phase was added to external aqueous phase consisting of known strength of PVA solution with continuous stirring on a mechanical stirrer (RQ-121/D, Remi Instrument Pvt., Ltd., Mumbai, India) at $1600 \mathrm{rpm}$ for $1.5 \mathrm{~h}$. The prepared NS were separated by centrifugation at $14500 \mathrm{rpm}$ at $-10^{\circ}$ for $90 \min ^{[18,19]}$.

\section{Design of the experiment:}

Design Expert ${ }^{\circledR}$ (10.0.0.1) program was used for statistical design of present NS formulation. The statistical software was utilized to acquire information not only about critical values required to achieve the desired response but also to study the possible interactions of the selected independent variables on the dependent variables. A design with 4 centre points and 4 points for lack of fit was used to obtain a robust model. Independent variables such as the amount of ethyl cellulose $\left(\mathrm{X}_{1}\right)$ and \% PVA $\left(\mathrm{X}_{2}\right)$ were used at low, medium and high levels as shown in Table 1. This design has provided 13 runs to study the effect of independent variables on two dependent variables namely particle size $\left(\mathrm{Y}_{1}\right)$ and $\%$ entrapment efficiency $\left(\mathrm{EE}, \mathrm{Y}_{2}\right)$. The amount of RS, volume of organic phase $(10 \mathrm{ml})$, stirring speed $(1600 \mathrm{rpm})$ and stirring time $(90 \mathrm{~min})$ were kept constant throughout the optimization process. For this design, statistical significance was set at 0.05 for the determination of probability values. The interaction between independent and dependent variables were graphically shown in contour plots and $3 \mathrm{D}$ surface response plots. The reliability of model was confirmed by check point analysis.

\section{EE determination:}

The prepared NS dispersion was centrifuged by aforementioned experimental parameters. Supernatant was separated, diluted and analysed spectroscopically at $262 \mathrm{~nm}$ to determine drug entrapment. Percent EE of the formulation was calculated as follows ${ }^{[20]}: \% \mathrm{EE}=$ [RS]total- $[\mathrm{RS}]$ supernatant/[RS]total $\times 100$, where $[\mathrm{RS}]$ total is the amount of total incorporated drug and [RS] supernatant is the amount of free drug in the supernatant layer.

\section{Measurement of particle size:}

The particle size of NS formulation was measured on a zeta sizer (Nano ZS, Malvern Instruments, Worcestershire, UK) after suitable dilution with distilled water.

\section{Determination of zeta potential and Fourier- transform infrared (FTIR) spectroscopy:}

Zeta potential is studied to characterize the surface charge properties of NS. It was measured on the Zetasizer after suitable dilution with distilled water. FTIR spectra were recorded on a FTIR spectrophotometer (IRAffinity-1, Shimadzu, Japan) to study any interaction between RS and the excipients. 
TABLE 1: VARIABLES AND LEVELS FOR STATISTICAL DESIGN

\begin{tabular}{lccc}
\hline Independent & \multicolumn{3}{c}{ Variables levels } \\
\cline { 2 - 4 } variables & Low (-1) & Medium (0) & High (1) \\
\hline $\mathrm{X}_{1}$ & 60 & 100 & 140 \\
$\mathrm{X}_{2}$ & 0.5 & 1.0 & 1.5 \\
\hline $\mathrm{X}_{1}=$ amount of ethyl cellulose $(\mathrm{mg}), \mathrm{X}_{2}=\%$ of PVA
\end{tabular}

Samples were mixed with $\mathrm{KBr}$ in a ratio of $1: 300$ and spectra were recorded in the range of $4000-400 \mathrm{~cm}^{-1}$.

\section{In vitro buoyancy studies:}

Accurately weighed amount of NS was placed in $0.1 \mathrm{~N}$ hydrochloric acid $(\mathrm{HCl})$. The mixture was stirred at $100 \mathrm{rpm}$ using a magnetic stirrer. At the end of $24 \mathrm{~h}$, the floated and settled NS were recovered and collected by centrifugation. Both the fractions of NS were dried by lyophilization (MSW-137, Macro Scientific Work Pvt Ltd, Delhi, India), weighed and buoyancy was determined as follows, buoyancy $(\%)=$ $\mathrm{W}_{\mathrm{F}} /\left(\mathrm{W}_{\mathrm{F}}+\mathrm{W}_{\mathrm{S}}\right) \times 100$, where $\mathrm{W}_{\mathrm{F}}$ is the weight of floating NS and $\mathrm{W}_{\mathrm{S}}$ is the weight of settled NS.

\section{In vitro drug release study:}

In vitro release study was carried out using dialysis sac method (HiMedia-Dialysis membrane 135, Mol. cut off 12 000-14 000 Da, Mumbai, India ${ }^{[20-22]}$. An accurately weighed amount of NS formulation equivalent to $10 \mathrm{mg}$ of RS was dispersed in $5 \mathrm{ml}$ of $0.1 \mathrm{~N} \mathrm{HCl}$ and introduced into the dialysis sac. The sac was hung in a glass beaker containing $100 \mathrm{ml}$ of $0.1 \mathrm{~N} \mathrm{HCl}$. The receptor compartment was stirred continuously at $37 \pm 0.5^{\circ}$ on a magnetic stirrer. Aliquots from receptor medium was withdrawn at predefined time intervals up to $24 \mathrm{~h}$ and replenishing each time with same volume of buffer. The samples were measured spectroscopically at $262 \mathrm{~nm}^{[23]}$.

\section{Surface morphology study:}

The surface morphology and shape of NS formulation were determined on a scanning electron microscope (SEM; Jeol JSM-5610LV, England). Prior to examination, the sample was mounted on to the metal stubs using a double-sided adhesive tape under vacuum. The equipment was operated with an acceleration voltage of $15 \mathrm{kV}$ and working distance of $20 \mu \mathrm{m}$. Images of NS were taken at various magnifications ${ }^{[24]}$.

\section{Differential scanning calorimetry (DSC) analysis:}

The thermograms of RS, physical mixture and optimized formulation were recorded on a DSC (TA60, Shimadzu, Japan). Samples were weighed in an aluminium pan and scanned in the temperature range of $50-300^{\circ}$ under dry nitrogen atmosphere at a heating rate of $10^{\circ} / \mathrm{min}$. The recorded thermograms were analysed for interaction between drug and excipients ${ }^{[20,24]}$.

\section{Stability study:}

A stability study was carried out for the optimized formulation as per International Conference on Harmonisation guidelines. The NS were placed in glass vials and stored at $25 \pm 2^{\circ} / 60 \pm 5 \% \mathrm{RH}$ and $40 \pm 2^{\circ} / 75 \pm$ $5 \%$ RH atmospheric conditions in a stability chamber (Macro Scientific Work Pvt. Ltd., Delhi, India) for a period of 1 mo. Samples were analysed for particle size, $\% \mathrm{EE}$ and in vitro drug release after the stability period.

\section{RESULTS AND DISCUSSION}

The solubility of RS was studied in various solvents such as methanol, ethanol and DCM. RS has satisfactory solubility in a single organic solvent. However in the preliminary studies, a problem was encountered after the addition of internal organic phase (a mixture of RS and polymer in a single solvent) into the external aqueous phase. RS was precipitated in the aqueous medium, which resulted in low entrapment of RS in NS. Thereafter, a solvent system such as methanol:DCM (1:1) and $\mathrm{KOH}$ in methanol was tried for dissolving the polymer and RS, respectively. The internal organic phase comprising of methanol:DCM and $\mathrm{KOH}$ in methanol increased RS stability in the external phase, which improved drug entrapment in formulation. Therefore, this mixture of solvents for internal organic phase was selected for the further optimization of NS.

Drug-loaded NS in different combinations were designed and prepared by modified quasi emulsion solvent diffusion technique. Various preliminary trials were carried out before the implementation of a statistical tool for the development of NS. Screening of stirring speed was performed between the range $1300-1900 \mathrm{rpm}$. At the minimum speed of $1300 \mathrm{rpm}$, lump formation of particles was observed. This might be due to insufficient rotation speed at which the NS were unable to get separated out. Ruptured particles with irregular surface morphology were found at high stirring speed of $1900 \mathrm{rpm}$. NS with discrete spherical particles and even surface were formed at a speed of $1600 \mathrm{rpm}$. Therefore, this speed was selected for further optimization of NS. Second important parameter studied during the preliminary trials was stirring time. Irregular particle formation was observed due to 
improper solvent evaporation after $1 \mathrm{~h}$ stirring, while particles were ruptured after $2 \mathrm{~h}$ of stirring due to increased stress on spongy particles. Uniform spherical particles were obtained after $1.5 \mathrm{~h}$ stirring; therefore it was selected for further optimization. Polymers such as Eudragit RS 100, Eudragit E 12.5 and ethyl cellulose were utilised in polymer screening process. Poor drug entrapment and irregular shape particles were observed when NS were prepared with Eudragit RS 100 and Eudragit E 12.5. NS prepared with ethyl cellulose showed uniform and discrete morphology with good drug entrapment, therefore this polymer was selected for further process.

Statistical correlation was evaluated among the factors and responses by means of statistical Design Expert ${ }^{\circledR}$ software. The statistical design has suggested 13 runs for optimization of NS formulation and all experiments were performed by considering 2 independent variables with 2 experimental responses as shown in Table 2. The primary stage in data analysis was to fit the investigational data for suitable model. An appropriate model was preferred by the statistical tool on the basis of various statistical parameters. Therefore, various models such as linear, quadratic, 2 FI and cubic were studied for experimental responses using predicted residual sum of square (PRESS) statistic for the identification of appropriateness of model fitting. The quadratic model was selected for both variables as it showed lowest value of PRESS measurement compared to other models. The $\mathrm{p}$ value was also found less than 0.05 that showed significance in the model fitting as per the ANOVA analysis. The following polynomial Eqns. were obtained to study the relationship between independent and dependent variables. $\mathrm{Y}_{1}=$ $139.4793+33.7 \mathrm{X}_{1}-10.43 \mathrm{X}_{2}+11.77 \mathrm{X}_{1}{ }^{2}+24.77 \mathrm{X}_{2}{ }^{2}-$ $0.77 \mathrm{X}_{1} \mathrm{X}_{2} ; \mathrm{Y}_{2}=66.00+10.25 \mathrm{X}_{1}+0.425 \mathrm{X}_{2}-11.89 \mathrm{X}_{1}{ }^{2}$ $9.60 \mathrm{X}_{2}^{2}-4.35 \mathrm{X}_{1} \mathrm{X}_{2}$.

The influence of independent variables on experimental responses is depicted graphically in the contour and 3D surface response plots as shown in fig. 1. The plots showed that particles size increases gradually with increase in drug to polymer ratio from 1:3, 1:5 to 1:7. The graph also depicted that, particles size increases with $0.5 \% \mathrm{w} / \mathrm{v}$ of PVA and decreases with $1 \% \mathrm{w} / \mathrm{v}$ of PVA. On the other end, it was found that the increment in drug to polymer ratio leads to more \% entrapment due to the more exposure of polymer environment to the drug. Overlay plot revealed in fig. 2 highlighted the area showing upper and lower limits of responses as a
TABLE2:FACTORIALLAYOUTANDEXPERIMENTAL RESPONSES FOR NANOSPONGES

\begin{tabular}{lcccc}
\hline \multirow{2}{*}{$\begin{array}{l}\text { Batch } \\
\text { code }\end{array}$} & \multicolumn{2}{c}{ Variable level } & \multicolumn{2}{c}{ Experimental responses } \\
\cline { 2 - 5 } & $\mathrm{X}_{1}$ & $\mathrm{X}_{2}$ & $\mathrm{Y}_{1}$ & $\mathrm{Y}_{2}$ \\
\hline $\mathrm{K} 1$ & -1 & -1 & $152.2 \pm 5.70$ & $31.5 \pm 2.50$ \\
$\mathrm{~K} 2$ & -1 & 0 & $117.4 \pm 6.19$ & $42.31 \pm 3.75$ \\
$\mathrm{~K} 3$ & -1 & 1 & $132.6 \pm 3.25$ & $38.54 \pm 0.42$ \\
$\mathrm{~K} 4$ & 0 & -1 & $174.5 \pm 4.79$ & $54.52 \pm 1.70$ \\
$\mathrm{~K} 5$ & 0 & 0 & $139.5 \pm 1.29$ & $65.48 \pm 3.51$ \\
$\mathrm{~K} 6$ & 0 & 1 & $154.2 \pm 5.18$ & $60.42 \pm 1.07$ \\
$\mathrm{~K} 7$ & 1 & -1 & $220.9 \pm 4.29$ & $58.11 \pm 2.33$ \\
$\mathrm{~K} 8$ & 1 & 0 & $185.3 \pm 4.73$ & $68.05 \pm 0.94$ \\
$\mathrm{~K} 9$ & 1 & 1 & $198.2 \pm 3.97$ & $47.72 \pm 1.06$ \\
$\mathrm{~K} 10$ & 0 & 0 & $138.2 \pm 2.56$ & $64.32 \pm 2.67$ \\
$\mathrm{~K} 11$ & 0 & 0 & $140.6 \pm 3.09$ & $65.14 \pm 3.45$ \\
$\mathrm{~K} 12$ & 0 & 0 & $137.8 \pm 4.61$ & $64.90 \pm 1.35$ \\
$\mathrm{~K} 13$ & 0 & 0 & $139.1 \pm 4.21$ & $65.39 \pm 2.75$ \\
\hline
\end{tabular}

Values are expressed as mean $\pm S D, n=3$

function of formulation components.

To set the objective for the selection of optimized formulation, composition of NS with maximum drug entrapment (\%) and minimum particle size (nm) was predicted by the software for check point analysis. The predicted formula with $112.64 \mathrm{mg}$ of ethyl cellulose and $1.13 \% \mathrm{w} / \mathrm{w}$ surfactant concentration was experimentally prepared in triplicate and studied for experimental responses. The practically obtained $\%$ entrapment and particle size were significantly identical with predicted values as shown in Table 3 . The NS showed considerably smaller mean particle size with less polydispersity index of $<0.20$ that represent narrow particles distribution within dispersion. The percent error for both responses was very less. Therefore, from this check point analysis it can be confirmed that applied statistical design is a reliable model for the optimization of drug-loaded NS.

Zeta potential greater than 30 imparted good stability to nanoparticles dispersion. The optimized formulation showed zeta potential value of $-35.4 \mathrm{mV}$. At this high potential, nanoparticles would exhibit a great repulsion with each other, which significantly prevented agglomeration of particles. Drug-polymer compatibility studies were carried out using FTIR spectroscopy to establish any possible interaction of drug with the polymer used in the formulation. Fig. 3 showed the presence of characteristic peaks of $\mathrm{RS}$ in the formulated NS without any significant change 

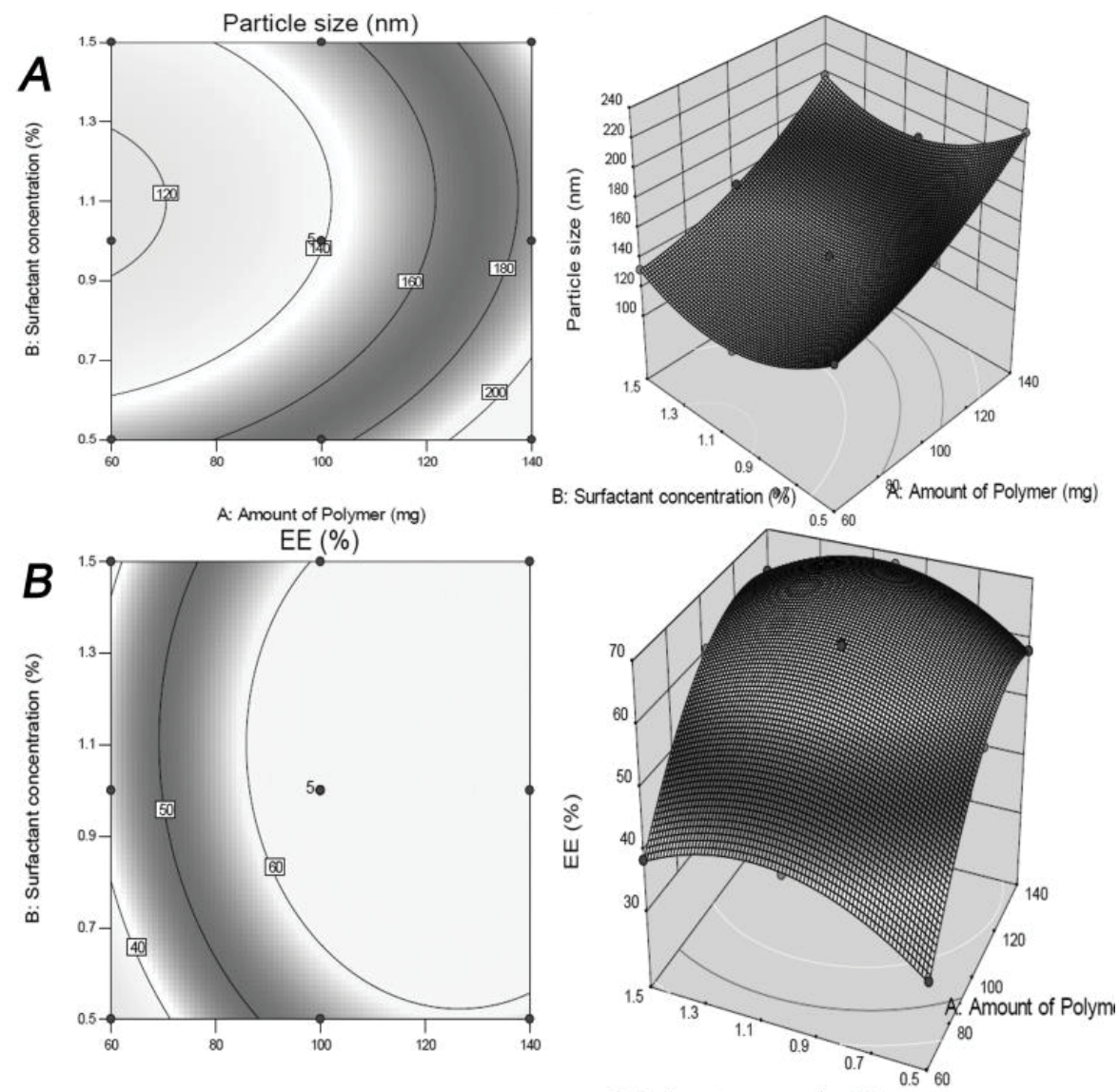

A: Amount of Polymer (mg)

B: Surfactant concentration (\%)

Fig. 1: Contour plots and 3D response surface plots

Graphical presentation showing the effect of independent variables on experimental responses of (A) particle size and (B) entrapment efficiency

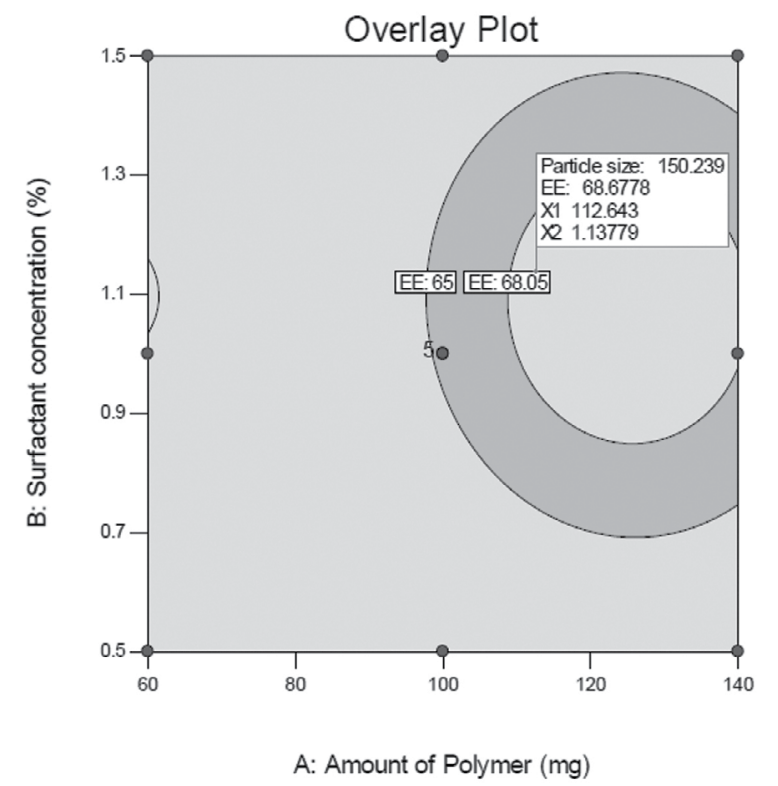

Fig. 2: Over lay plot

Over lay plot highlighting the region from which optimization was carried out. $\bullet$ Represent design points

in their position indicating no chemical interaction between RS and the excipients. The buoyancy study showed that $85.10 \pm 0.71 \%$ of NS was remained buoyant
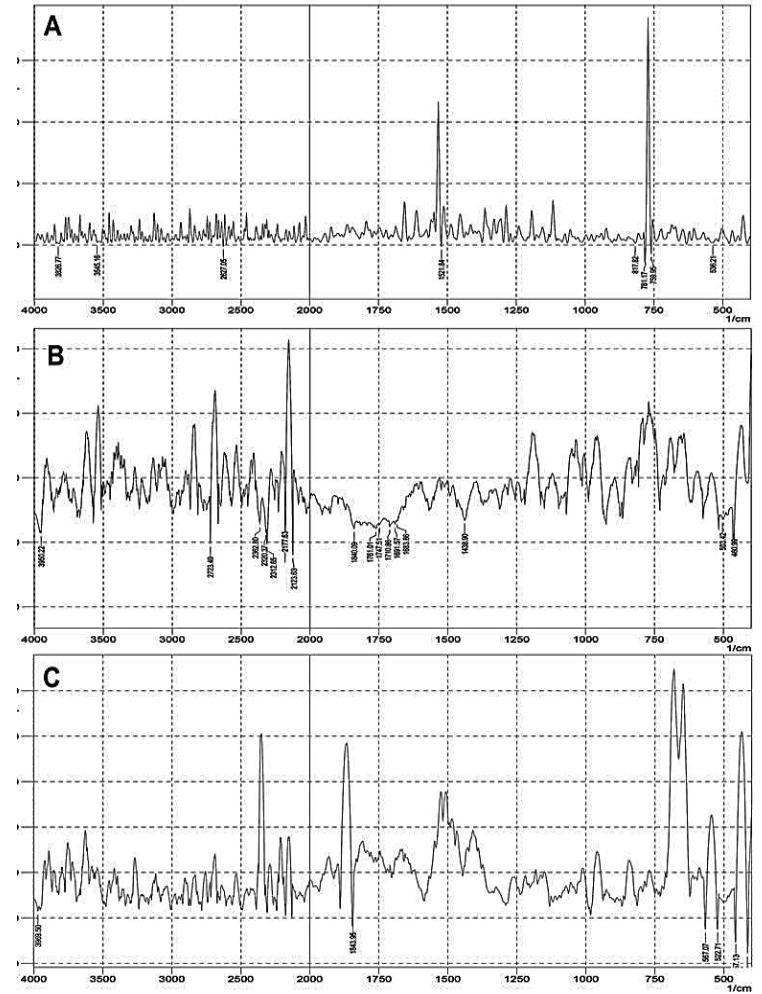

Fig. 3: FTIR spectra

A. Risedronate sodium (RS) B. physical mixture of ethyl cellulose and risedronate and $\mathrm{C}$. optimized nanosponge (NS) formulation 
after $24 \mathrm{~h}$. This showed good stability of NS in acidic media and provide an environment for the maximum absorption of drug from the acidic medium. Hence, it has been concluded that optimized NS was remained in acidic media for the longer period of time $(>24 \mathrm{~h})$ which is essential prerequisite for the absorption of drug from acidic environment for the better therapeutic performance of drug.

In vitro release profile of $\mathrm{RS}$ from optimized formulation portrayed in fig. 4 showed burst release of RS for initial $2 \mathrm{~h}$ followed by slow and sustained release up to $24 \mathrm{~h}$. Initial burst release might be due to the adsorbed RS on the surface, which might get released at a faster rate compared to RS entrapped inside the core of NS. The matrix of NSs held RS and controlled the release over the longer period of time. Different kinetic models were applied to find out the release behaviour of the optimized formulation. The release kinetics of the optimized formulation has high linearity for Higuchi model with regression coefficient

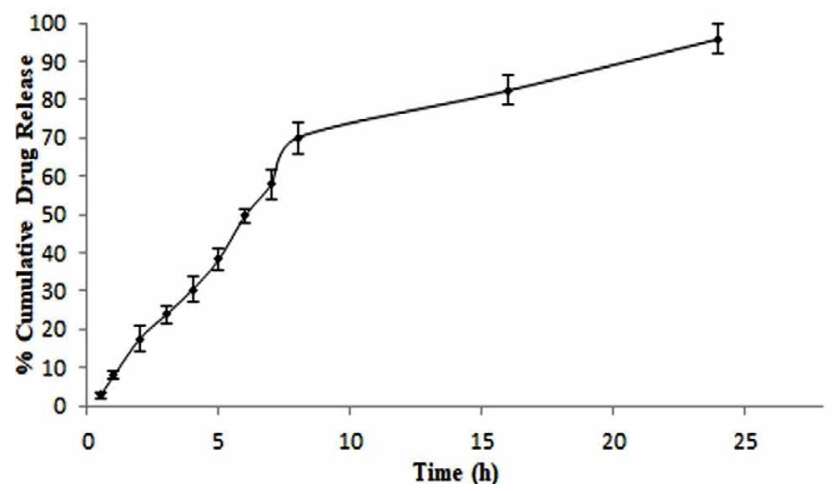

Fig. 4: In vitro release profile of optimized formulation, $n=3$

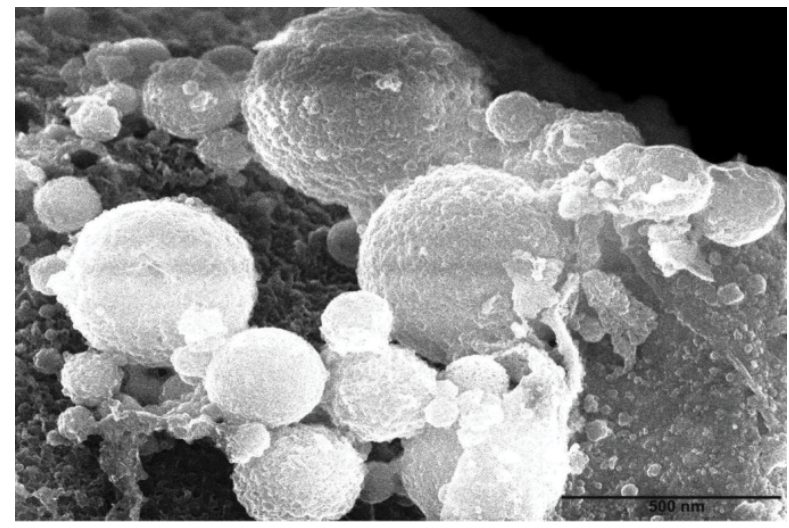

Fig. 5: SEM analysis of risedronate-loaded nanosponges 20000X
$\left(\mathrm{R}^{2}\right)$ value of 0.939 . Thus, from all this discussion it could be concluded that optimized NS formulation followed diffusion-controlled release mechanism as per the Higuchi model.

SEM image of diluted sample of NS in fig. 5 showed discrete spherical particles with porous surface. The figure showed that the particles were uniformly distributed without any agglomeration. SEM analysis confirmed the nano scale range of the optimized formulation, which was supported by the data obtained from particle size analysis.

The thermogram in fig. 6A of pure RS showed sharp endothermic peak at $263.78^{\circ}$ corresponding to its melting point indicating crystalline nature of pure drug. Fig. 6B represents thermogram of physical mixture of RS and ethyl cellulose with endothermic peaks at $262.12^{\circ}$ and $176.13^{\circ}$ showing their melting points, respectively. The thermogram in fig. $6 \mathrm{C}$ for the optimized formulation depicted peaks of polymer and RS at expected places without any variation. The endothermic peak of RS is considerably broadened indicating a decline in crystallinity of RS in NS formulation.

The stability study of optimized formulation was carried out for the period of $1 \mathrm{mo}$ with the specified storage conditions. The EE (\%), particle size and in vitro drug release study were evaluated at the end of study as shown in Table 4. It was found that there were no significant changes in the formulation with respect to performed evaluation parameters and thus, it could be concluded that formulation was stable after 1 mo stability study. The result of optimized formulation

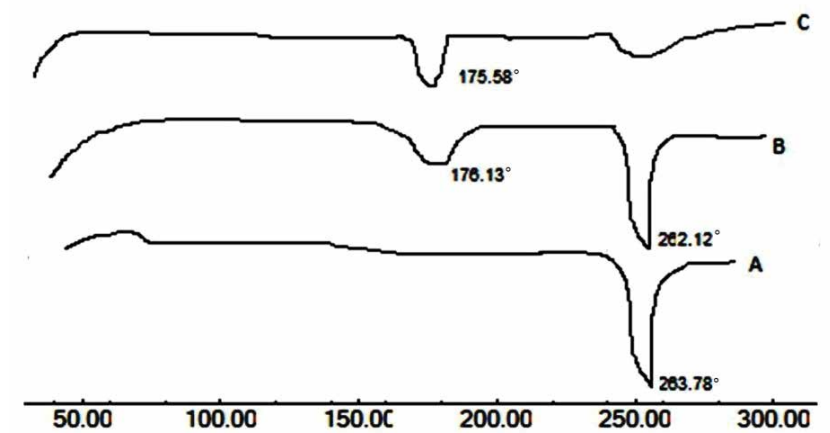

Fig. 6: DSC thermograms

A. Risedronate sodium (RS), B. physical mixture and C. optimized nanosponge (NS) formulation

TABLE 3: CHECK POINT ANALYSIS FOR SELECTED MODEL

\begin{tabular}{lccccc}
\hline Independent variables & Experimental variables & Predicted value & Observed value \pm SD & Residual & $\%$ Error \\
\hline$X_{1}-112.64 \mathrm{mg}$ & $Y_{1}(\mathrm{~nm})$ & 150.24 & $155.8 \pm 2.17$ & 5.56 & 3.56 \\
$\mathrm{X}_{2}-1.13 \% \mathrm{~W} / \mathrm{W}$ & $\mathrm{Y}_{2}(\%)$ & 68.67 & $67.27 \pm 1.05$ & -1.4 & -3.52 \\
\hline
\end{tabular}

Values are expressed as mean $\pm S D, n=3$ 


\begin{tabular}{lccc}
\hline Parameters & \multirow{2}{*}{ Before stability study } & \multicolumn{2}{c}{ After stability study } \\
\cline { 3 - 4 } & & $40 \pm 2^{\circ} / 75 \pm 5 \% \mathrm{RH}$ & $\mathbf{2 5 \pm 2} / 60 \pm 5 \% \mathrm{RH}$ \\
\hline Particle size \pm SD $(\mathrm{nm})$ & $139.5 \pm 1.29$ & $137.95 \pm 2.10$ & $138.52 \pm 2.83$ \\
Entrapment efficiency $\pm \mathrm{SD}(\%)$ & $65.48 \pm 3.51$ & $63.96 \pm 2.57$ & $64.05 \pm 1.95$ \\
In vitro drug & $95.83 \pm 5.32$ & $93.96 \pm 2.21$ & $94.35 \pm 3.07$ \\
release study \pm SD & &
\end{tabular}

Values are expressed as mean $\pm S D, n=3$

found at accelerated conditions $(40 \pm 2 \% / 75 \pm 5 \% \mathrm{RH})$ may produce long term reliability of formulation besides the studied period.

The declarations made in present research work are based on the various in vitro studies of the formulation. The present research work concludes that the permeability and bioavailability of BCS class III drugs may be improved if delivered in the form of NS but this statement can be supported only after performing in vivo study. In this research work, an effort was made to formulate NS using modified quasi-emulsion solvent diffusion technique for the improvement in permeability by the GI retention of drug. The work further concludes that the concentration of polymer ethyl cellulose $(100 \mathrm{mg})$ and stabilizer PVA $(1 \% \mathrm{w} / \mathrm{v})$ play a key role in the optimization of the formulation. The particle size and \% EE of drug were vary with the different concentrations of the polymer and the stabilizing agent. The full $3^{2}$ factorial design represents that the optimized NS showed $155.8 \pm 2.17 \mathrm{~nm}$ particle size and $67.27 \pm 1.05 \%$ EE with sustained drug release up to $24 \mathrm{~h}$. The formulation was remained buoyant up to $24 \mathrm{~h}$ that provides the GI absorption of drug. The stability study also showed satisfactory findings with all evaluated parameters. This work concludes that the NSs of the RS could be an exceptional drug delivery system for better management of osteoporosis.

\section{Acknowledgements:}

The authors thank Manus Aktteva Biopharma LLP, Ahmedabad, for providing gift sample of RS for this research work. Authors also wish to thank the Department of Pharmacy, Sumandeep Vidyapeeth, Piparia, Vadodara, for providing required facilities to carry out this research work.

\section{Conflict of interest:}

The authors declare no conflict of interest.

\section{REFERENCES}

1. Kanis J, Black D, Cooper C, Dargent P, Dawson-Hughes B, De Laet C, et al. A new approach to the development of assessment guidelines for osteoporosis. Osteoporosis Int 2002;13(7):527-36.

2. Kanis JA, Melton LJ, Christiansen C, Johnston CC, Khaltaev N. The diagnosis of osteoporosis. J Bone Miner Res 1994;9(8):1137-41.

3. Rawat P, Ahmad I, Vohora D, Ahmad FJ, Talegaonkar S. Three Ply-Walled Microcapsules for Enhanced Pharmacokinetics of Poorly Absorbed Risedronate Sodium: Novel Stratagem Toward Osteoporosis. J Pharm Innov 2015;10(2):130-9.

4. Osteoporosis Prevention, Diagnosis, and Therapy. NIH Consens Statement 2000;17(1):1-45.

5. Brown JP, Josse RG. 2002 clinical practice guidelines for the diagnosis and management of osteoporosis in Canada. CMAJ 2002;167(10):S1-S34.

6. Neer RM, Arnaud CD, Zanchetta JR, Prince R, Gaich GA, Reginster JY, et al. Effect of parathyroid hormone (1-34) on fractures and bone mineral density in postmenopausal women with osteoporosis. N Engl J Med 2001;344(19):1434-41.

7. Watts NB. Bisphosphonate treatment of osteoporosis. Clin Geriatr Med 2003;19(2):395-414.

8. Biernacka J, Betlejewska-Kielak K, Klosinska-Szmurlo E, Plucinski FA, Mazurek AP. Prediction of bioavailability of selected bisphosphonates using in silico methods towards categorization into a biopharmaceutical classification system. Acta Pol Pharm 2013;70(5):877-82.

9. Dave VS, Gupta D, Yu M, Nguyen P, Varghese, Gupta S. Current and evolving approaches for improving the oral permeability of BCS Class III or analogous molecules. Drug Dev Ind Pharm 2017;43(2):177-89.

10. Mitchell DY, Heise MA, Pallone KA, Clay ME, Nesbitt JD, Russell DA, et al. The effect of dosing regimen on the pharmacokinetics of risedronate. $\mathrm{Br} \mathrm{J}$ Clin Pharmacol 1999;48(4):536-42.

11. Singh BN, Kim KH. Floating drug delivery systems: an approach to oral controlled drug delivery via gastric retention. J Control Release 2000;63(3):235-59.

12. Silverman S, Watts N, Delmas P, Lange J, Lindsay R. Effectiveness of bisphosphonates on nonvertebral and hip fractures in the first year of therapy: the risedronate and alendronate (REAL) cohort study. Osteoporosis Int 2007;18(1):25-34.

13. Selvamuthukumar S, Anandam S, Kannan K, Manavalan R. Nanosponges: A novel class of drug delivery system-review. J Pharm Pharm Sci 2012;15(1):103-11.

14. Tamkhane V, Sharma P. Nanosponge-A Novel Drug Delivery System. Int J Curr Pharm Res 2014;4:1186-93.

15. Tambe R, Battase P, Arane P, Palve S, Talele S, Chaudhari G. Review on nanosponges: As a targeted drug delivery system. Am J PharmTech Res 2015;5:215-24.

16. Vishwakarma A, Nikam P, Mogal R, Talele S. Review on nanosponges: A benefication for novel drug delivery. Int $\mathrm{J}$ PharmTech Res 2014;6:11-20. 
17. Shringirishi M, Prajapati SK, Mahor A, Alok S, Yadav P, Verma A. Nanosponges: a potential nanocarrier for novel drug delivery-a review. Asian Pac J Trop Dis 2014;4:S519-S526.

18. Srinivas P, Sreeja K. Formulation and evaluation of voriconazole loaded nanosponges for oral and topical delivery. Int J Drug Dev Res 2013;5(1):55-69.

19. Guo L, Gao G, Liu X, Liu F. Preparation and characterization of $\mathrm{TiO}_{2}$ nanosponge. Mater Chem Phys 2008;111(2):322-5.

20. Shah NV, Seth AK, Balaraman R, Aundhia CJ, Maheshwari RA, Parmar GR. Nanostructured lipid carriers for oral bioavailability enhancement of raloxifene: Design and in vivo study. J Adv Drug Res 2016;7(3):423-34.

21. Shah N, Seth AK, Balaraman R, Sailor G, Javia A, Gohil D. Oral bioavailability enhancement of raloxifene by developing microemulsion using D-optimal mixture design: optimization and in vivo pharmacokinetic study. Drug Dev Ind Pharm 2018;44(4):687-96.

22. Shah NV, Ghelani TK, Saini V, Joshi UT, Seth AK, Chauhan $\mathrm{SP}$, et al. Development and characterization of microemulsion based system of aceclofenac. Indo Am J Pharm Res 2011;1:110-24.

23. Shah NV, Sheth NS, Mistry RB, Seth AK, Shah PM, Shah NC. In vitro release of diclofenac sodium from different topical vehicles. Pharm Sci Monit 2011;2(2);S31-S39.

24. Shah N, Seth AK, Balaraman R. Bioavailability enhancement of poorly soluble raloxifene by designing inclusion comlpex with $\beta$ - cyclodextrin. Int J Pharm Pharm Sci 2015;7(8):205-11. 